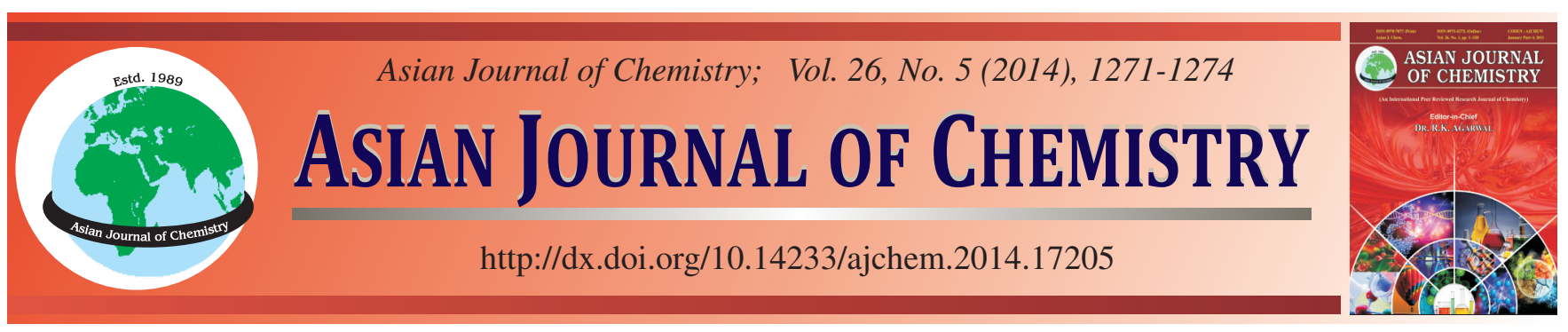

\title{
Desorption of Metals from Aquifer Soils During Infiltration of Low Ionic Strength Water by pH Effect $\dagger$
}

\author{
Xianhuai Huang ${ }^{1,2, *}$, Junje Xue ${ }^{1}$, Qilin $\mathrm{Li}^{3}$ and Yuchao Tang ${ }^{1,2}$
}

${ }^{1}$ School of Environmental and Energy Engineering, Anhui Jianzhu University, Hefei 230601, P.R. China

${ }^{2}$ Key Lab of Water Pollution Control and Wastewater Resource in Anhui Province, Hefei 230601, P.R. China

${ }^{3}$ Department of Civil and Environmental Engineering, Rice University, Texas 77005, USA

*Corresponding author: Fax: +86 551 63828062; Tel: +86 551 63828060; E-mail: xhhuang2@ gmail.com

Primary and trace metals from S400 samples are higher than that from S700 because the size of S400 is smaller than one of S700. The effects of solution chemistry, i.e., ionic strength and $\mathrm{pH}$, on metal immobilization were evaluated via batch desorption equilibrium experiments for aquifer soils during infiltration of low ionic strength water. For S400 and S700, cumulative desorption amount of Ca is, respectively 2050 and $1900 \mathrm{mg} / \mathrm{kg}$-soil with 12 times extraction at $58 \mathrm{mg} / \mathrm{L}$ of TDS water at $\mathrm{pH}=4$. It was found that desorption of Ca, $\mathrm{Mg}$ and $\mathrm{Ba}$ decreases with increasing $\mathrm{pH}$. For S400 and S700, cumulative desorption amount of As is $0.9 \mathrm{mg} / \mathrm{kg}$-soil with 15 times extraction at $58 \mathrm{mg} / \mathrm{L}$ of TDS water at $\mathrm{pH}=9$. On the contrary, desorption of As was found to increase slightly with increasing solution $\mathrm{pH}$, although the effect of $\mathrm{pH}$ is not as great as that for the other metals. This effect was offset by the less dissolution of $\mathrm{CaCO}_{3}$ at higher $\mathrm{pH}$, which reduced release of carbonate associated arsenic.

Keywords: Desorption of metals, Aquifer soils, Infiltration of low ionic strength water, pH effect.

\section{INTRODUCTION}

Artificial recharge using source waters of impaired quality can potentially introduce microbial, inorganic and organic contaminants into groundwater. Meanwhile, biochemical and geochemical reactions between the recharge water and the aquifer materials may lead to mobilization of inorganic species that are part of the mineral framework of the aquifer.

Metals, unlike hazardous organics, cannot be degraded. In addition to the primary metals, a number of heavy metals are naturally present in soil, such as $\mathrm{Cu}, \mathrm{As}, \mathrm{Cr}, \mathrm{Pb}, \mathrm{Ni}$ and $\mathrm{Co}$. Many soils in arid areas contain naturally occurring, easily leachable contaminants of relevance to drinking water quality, notably $\mathrm{F}, \mathrm{B}, \mathrm{As}, \mathrm{Cr}, \mathrm{Pb}$ and $\mathrm{Ba}^{1}$. Interactions between metals and soil mainly involve precipitation/dissolution and sorption/ desorption. The effects of solution chemistry, i.e., ionic strength and $\mathrm{pH}$, on metal immobilization were evaluated via batch desorption equilibrium experiments in this study. The research objective is to evaluate the potential for release of metals of public concern from surface infiltration operations when reclaimed water of low TDS is used for recharge.

\section{EXPERIMENTAL}

Recharge water and soil samples: Reclaimed water with municipal wastewater treated to drinking water quality using microfiltration and reverse osmosis (referred to as $\mathrm{RO}$ water) was used as the model low ionic strength recharge water. The reverse osmosis water is one of the two recharge waters currently used for vadose zone injection at the Water Campus Project (WCP) in the City of Scottsdale, AZ, USA.

At the WCP site, both the top layer, from the surface to approximately $200 \mathrm{ft}$ and the aquifer, approximately $550 \mathrm{ft}$ below the ground surface, are sand dominated with silt and gravel, with silt dominated soils in between. Well \#140 was drilled using a reverse circulation rotary drilling method near the WCP recharge site. Drill cuttings at the depth of 180', 400', 550' and 700' (designated S180, S400, S550 and S700, respectively) were collected in polyethylene freezer bags and kept in new 1-gallon paint cans by the hydrogeologist for the Water Resource Department, City of Scottsdale, AZ, USA.

Water sample analysis and soil characterization: Table1 lists some water quality parameters relevant to this study. 


\begin{tabular}{lcc}
\hline \multicolumn{3}{c}{ TABLE-1 } \\
\multicolumn{2}{|c}{$\begin{array}{c}\text { RELEVANT WATER QUALITY DATA FOR RO } \\
\text { WATERS AT WATER CAMPUS PROJECT }\end{array}$} \\
\cline { 2 - 3 } \multicolumn{2}{c}{ Water quality } & RO \\
\cline { 2 - 3 } & Mean & SD \\
\hline $\mathrm{pH}$ & 6 & 0.11 \\
Total alkalinity $\left(\mathrm{mg} / \mathrm{L}\right.$ as $\left.\mathrm{CaCO}_{3}\right)$ & 19 & 0.24 \\
TOC $(\mathrm{mg} / \mathrm{L})$ & 0.4 & 0.13 \\
TDS $(\mathrm{mg} / \mathrm{L})$ & 25.6 & 3.2 \\
Conductivity $(\mu \mathrm{s})$ & 50.6 & 0.25 \\
\hline
\end{tabular}

All water and soil samples were analyzed in duplicate. Blank extraction tests were performed in parallel with samples for each extraction method following exactly the same procedure for soil samples.

Major soil characteristics important to sorption/desorption of heavy metals include mineralogical composition, hygroscopic moisture, soil $\mathrm{pH}$, particle size distribution, specific surface area, pore size distribution, organic matter, cation exchange capacity and total metal load. All soil characterization tests were conducted using soil fractions smaller than $2 \mathrm{~mm}$ in diameter, which were thoroughly mixed before use. Analytical methods used for soil characterization are summarized in Table- 2 .

TABLE-2

ANALYTICAL METHODS FOR SOIL CHARACTERIZATION

\section{Soil characteristics}

Mineralogical composition $\quad$ XRD to identify major mineral phases

Major element analysis

Hygroscopic moisture SEM-EDS

Analysis of weigh loss after oven dried at $105^{\circ} \mathrm{C}$

Particle size distribution Sieve analysis using ASTM standard sieves

Bet surface area

Pore size distribution

Organic content

$\mathrm{N}_{2}$ adsorption/desorption

$\mathrm{N}_{2}$ adsorption/desorption

Analysis of weight loss after heating at $400{ }^{\circ} \mathrm{C}$ for $4 \mathrm{~h}^{2,3}$

Metal concentration $\quad$ Wet extraction followed by ICP or ICPMS analysis

Cation exchange capacity The Palemio and Rhoades ${ }^{4}$

Total metal analysis was performed using the EPA 3050B method $^{5}$. This method determines total metal concentrations in soil that are "environmentally available".

Desorption equilibrium experiments: For all experiments, $1 \mathrm{~g}$ of soil was mixed with $15 \mathrm{~mL}$ desorption solution in a $20 \mathrm{~mL}$ polypropylene tube. The suspension was equilibrated for $20 \mathrm{~h}$ on a rotary shaker (Vibrax*VXR, VWR) at 30 rpm with $9,610 \mathrm{G}$, followed by $10 \mathrm{~min}$ of centrifugation. The clear supernatant was decanted, filtered through a membrane syringe filter and then collected in a $10 \mathrm{~mL}$ polypropylene plastic centrifuge tube for analysis of target metal concentrations.

\section{RESULTS AND DISCUSSION}

Soil properties: Table-3 summarizes some general properties of the soil samples. The total concentrations of some metals of soil samples are summarized in Table-4. The particle size distributions of soil samples collected from the Water Campus Project (WCP) site are shown in Fig. 1.

\begin{tabular}{|c|c|c|c|c|}
\hline \multicolumn{5}{|c|}{$\begin{array}{c}\text { TABLE-3 } \\
\text { GENERAL CHARACTERISTICS OF SOIL SAMPLES AT WCP }\end{array}$} \\
\hline Sampling ID & $\mathrm{S} 180$ & S400 & S550 & S700 \\
\hline $\mathrm{pH}$ & 8.8 & 8.2 & 8.8 & 8.9 \\
\hline Hygroscopic moisture (\%) & 1.2 & 2.8 & 1.2 & 1.0 \\
\hline Organic matter $(\mathrm{g} / \mathrm{kg})$ & 18.1 & 13.4 & 9.7 & 8.3 \\
\hline CEC (meq/100 g-soil) & 3.3 & 12.6 & 2.5 & 2.3 \\
\hline BET surface area $\left(\mathrm{m}^{2} / \mathrm{g}\right)$ & 7.63 & 18.87 & 5.4 & 2.25 \\
\hline
\end{tabular}

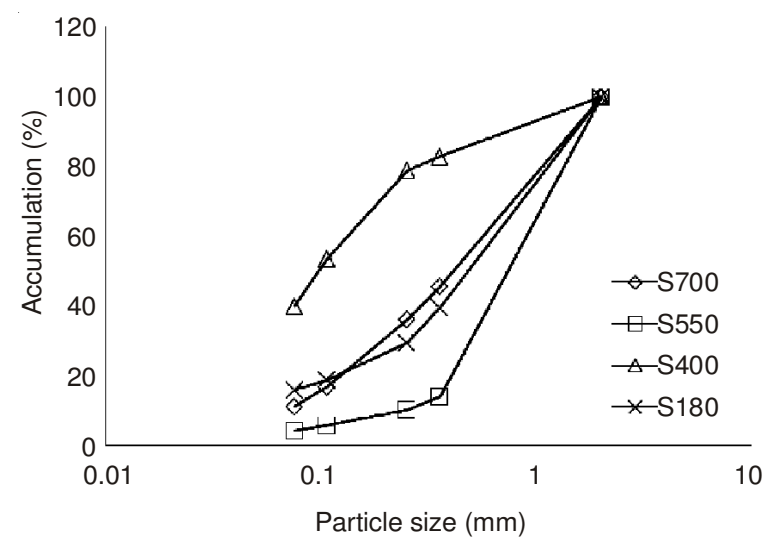

Fig. 1. Particle size distribution of soil samples from the WCP site

Fig. 2 presents the total metal concentrations in the soil samples. Only data for S400 and S700 are presented. Primary and trace metals from $\mathrm{S} 400$ samples are higher than that from S700 because the size of S400 is smaller than one of S700 (Fig. 1).

\section{Metal desorption equilibrium}

Effect of pH: It was found that desorption of $\mathrm{Ca}, \mathrm{Mg}$ and $\mathrm{Ba}$ decreases with increasing pH. Fig. 3 presents the amount of Ca desorbed from $\mathrm{S} 400$ and $\mathrm{S} 700$ as a function of cumulative desorption solution volume. For S400 and S700 samples, cumulative desorption amount of $\mathrm{Ca}$ is, respectively 2050 and

\begin{tabular}{|c|c|c|c|c|c|c|c|c|}
\hline \multirow{3}{*}{$\begin{array}{l}\text { Metal } \\
(\mathrm{mg} / \mathrm{kg})\end{array}$} & \multicolumn{8}{|c|}{$\begin{array}{c}\text { TABLE-4 } \\
\text { SOME METAL CONTENTS OF SOIL SAMPLE }\end{array}$} \\
\hline & \multicolumn{2}{|c|}{$\mathrm{S} 180$} & \multicolumn{2}{|c|}{ S400 } & \multicolumn{2}{|c|}{ S550 } & \multicolumn{2}{|c|}{ S700 } \\
\hline & Mean & SD & Mean & SD & Mean & SD & Mean & SD \\
\hline $\mathrm{Ca}$ & 14600 & 410 & 24125 & 757 & 11690 & 560 & 6997 & 400 \\
\hline $\mathrm{Mg}$ & 2727 & 33.2 & 7092 & 232 & 2434 & 45 & 2326 & 133 \\
\hline $\mathrm{Fe}$ & 4583 & 139 & 11340 & 339 & 5051 & 86 & 5516 & 363 \\
\hline $\mathrm{Al}$ & 3702 & 85.6 & 9694 & 461 & 3427 & 118 & 3369 & 249 \\
\hline As & 1.3 & 0.1 & 3.5 & 0.1 & 1.8 & 0.1 & 2.1 & 0.2 \\
\hline $\mathrm{Cr}$ & 4.2 & 0.1 & 8.8 & 0.2 & 5.3 & 0.2 & 6.1 & 0.1 \\
\hline $\mathrm{Pb}$ & 2.5 & 0.3 & 0.3 & 5.6 & 1.2 & 2.4 & 0.1 & 2.3 \\
\hline $\mathrm{Zn}$ & 14 & 1.3 & 20.3 & 1.0 & 11.2 & 1.6 & 14 & 0.1 \\
\hline
\end{tabular}


Primary metals in WCP soil

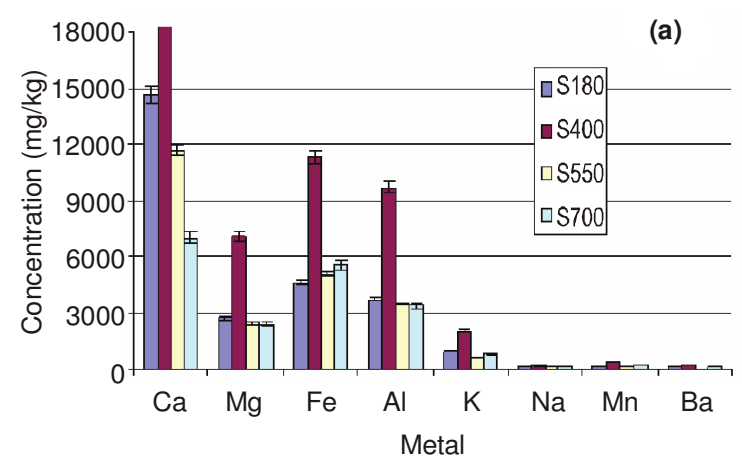

Trace metals in WCP soil

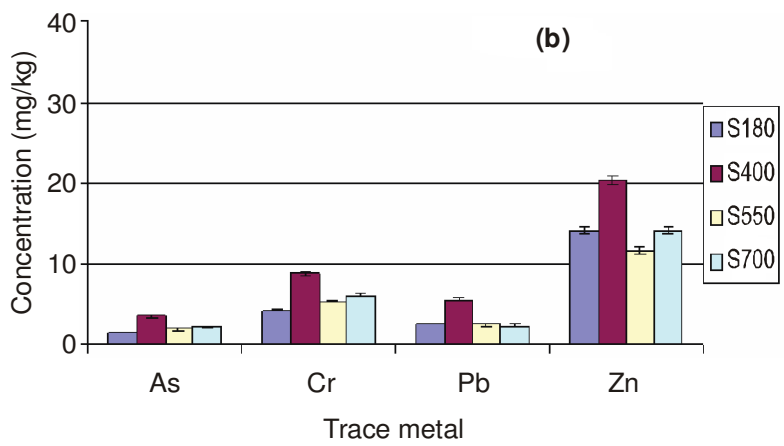

Fig. 2. Primary and trace metal contents of soil samples as (a) and (b)
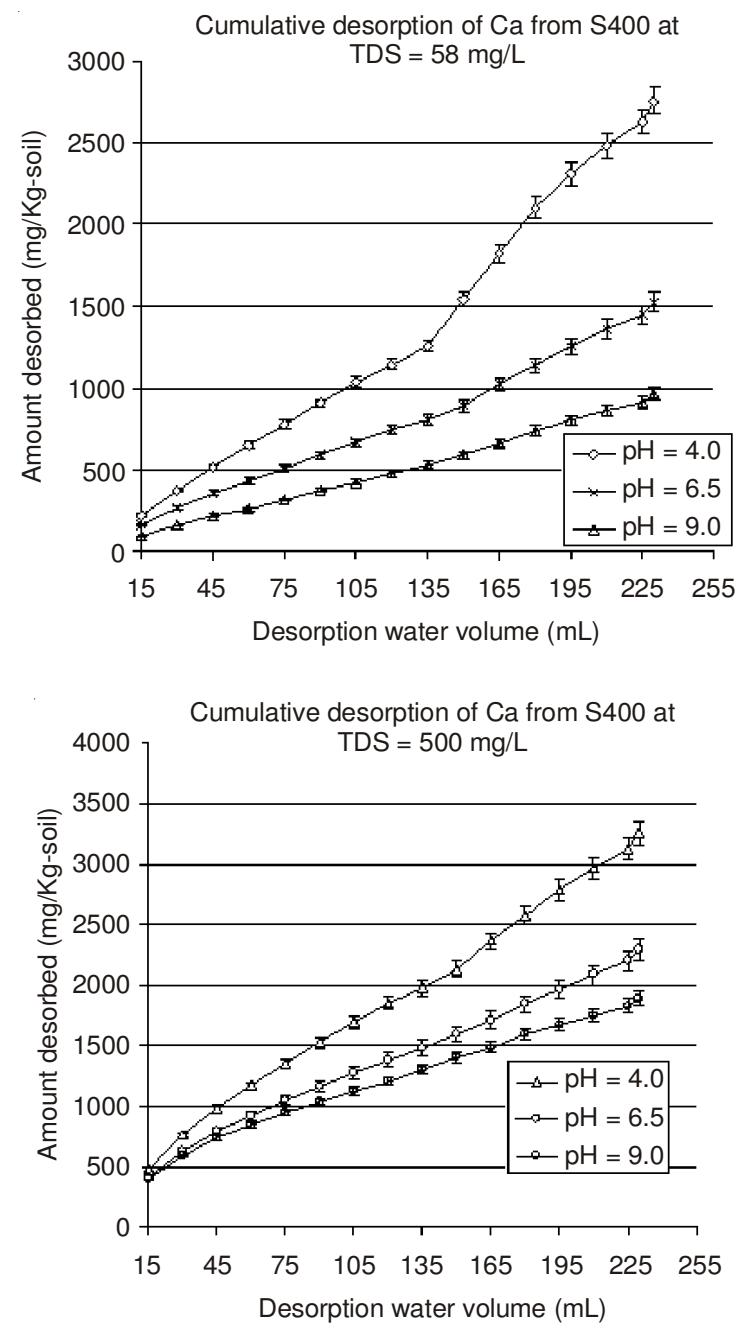

Cumulative desorption of $\mathrm{Ca}$ from $\mathrm{S} 700$ at $\mathrm{TDS}=58 \mathrm{mg} / \mathrm{L}$

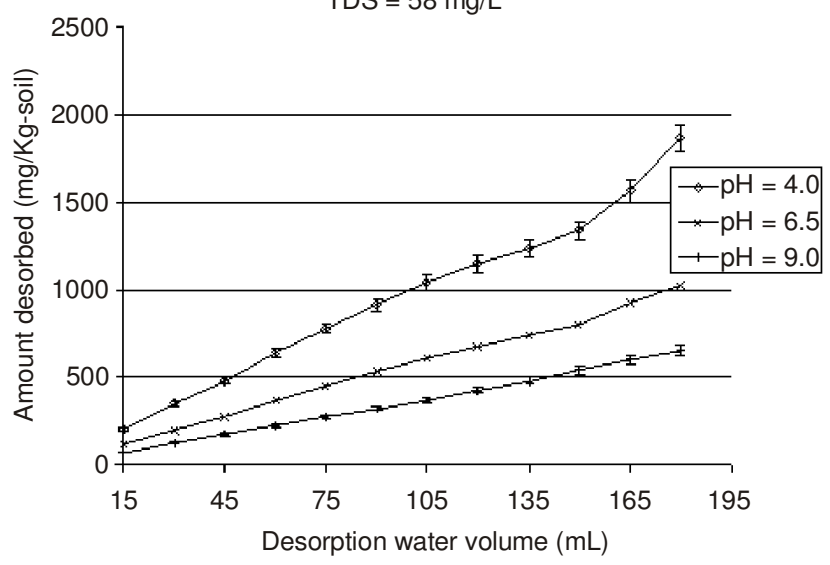

Cumulative desorption of $\mathrm{Ca}$ from $\mathrm{S} 700$ at $\mathrm{TDS}=500 \mathrm{mg} / \mathrm{L}$

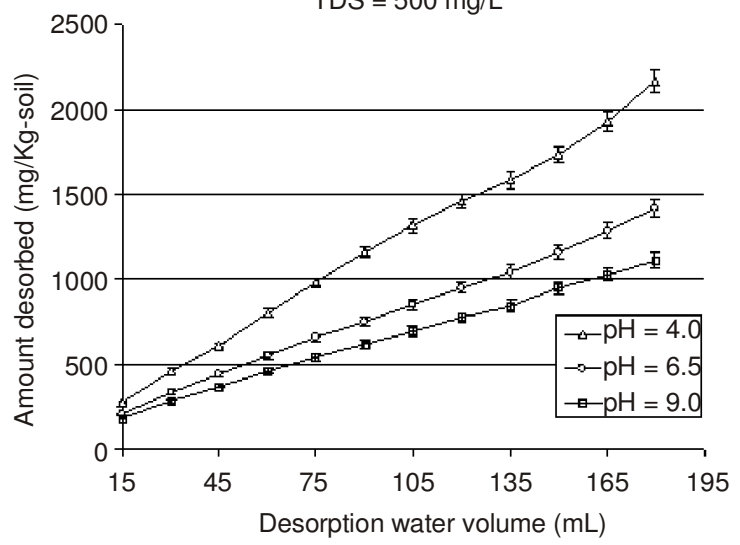

Fig. 3. Effect of pH on cumulative desorption of Ca from S400 and S700

$1900 \mathrm{mg} / \mathrm{kg}$-soil with 12 times extraction at $58 \mathrm{mg} / \mathrm{L}$ of TDS water at $\mathrm{pH}=4$. Results for $\mathrm{Mg}$ and $\mathrm{Ba}$ show the same trend with the amount desorbed one and three orders of magnitude lower, respectively. Desorption of cations from clay and a variety of oxides at low $\mathrm{pH}$ has been reported in a number of studies $^{6-8}$.

For S400 and S700 samples, cumulative desorption amount of arsenic is $0.9 \mathrm{mg} / \mathrm{kg}$ with 15 times extraction at 58 $\mathrm{mg} / \mathrm{L}$ of TDS water at $\mathrm{pH}=9$. On the contrary, desorption of arsenic was found to increase slightly with increasing solution $\mathrm{pH}$ (Fig. 4), although the effect of $\mathrm{pH}$ is not as great as that for the other metals. The slightly higher desorption at higher $\mathrm{pH}$ is consistent with the lower adsorption of arsenic reported at high pHs. Typically, arsenic exists in soils as either arsenate $\left(\mathrm{AsO}_{4}{ }^{3-}\right)$, or arsenite, $\left(\mathrm{AsO}_{3}{ }^{3-}\right)$. Because both arsenic acid $\left(\mathrm{H}_{3} \mathrm{AsO}_{4}\right)$ and arsenious acid $\left(\mathrm{As}(\mathrm{OH})_{3}\right)$ are weak acids, their speciation strongly depends on $\mathrm{pH}$. The pKa values of $\mathrm{H}_{3} \mathrm{AsO}_{4}$ and $\mathrm{As}(\mathrm{OH})_{3}$ are listed in Table-5. Based on the high calcite content of the soil samples and the high amount of Ca released, it is postulated that part of the arsenic desorption is from dissolution of $\mathrm{CaCO}_{3}$ and hence release of arsenic associated with it. The small impact of $\mathrm{pH}$ on arsenic desorption may be the result of these two contradicting mechanisms.

Desorption of all metals from S700 soil sample is lower than that from S400. This is consistent with the higher total metal contents, higher surface area and CEC of S400, as shown in Table-3. The soil has strong buffering capacity because 
Cumulative desorption of As from S400 at TDS $=58 \mathrm{mg} / \mathrm{L}$

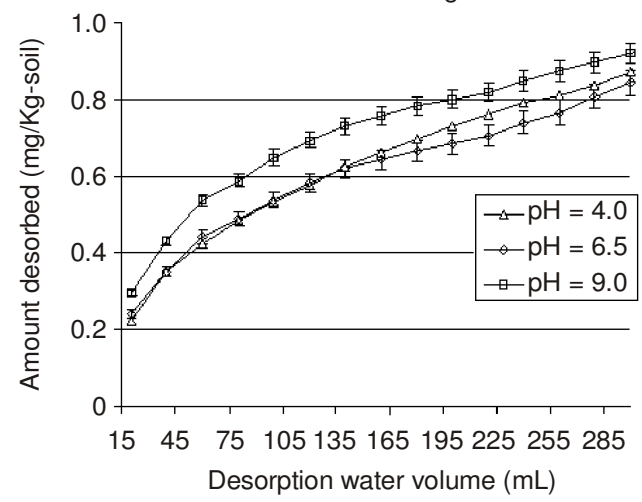

Cumulative desorption of As from S400 at TDS $=500 \mathrm{mg} / \mathrm{L}$
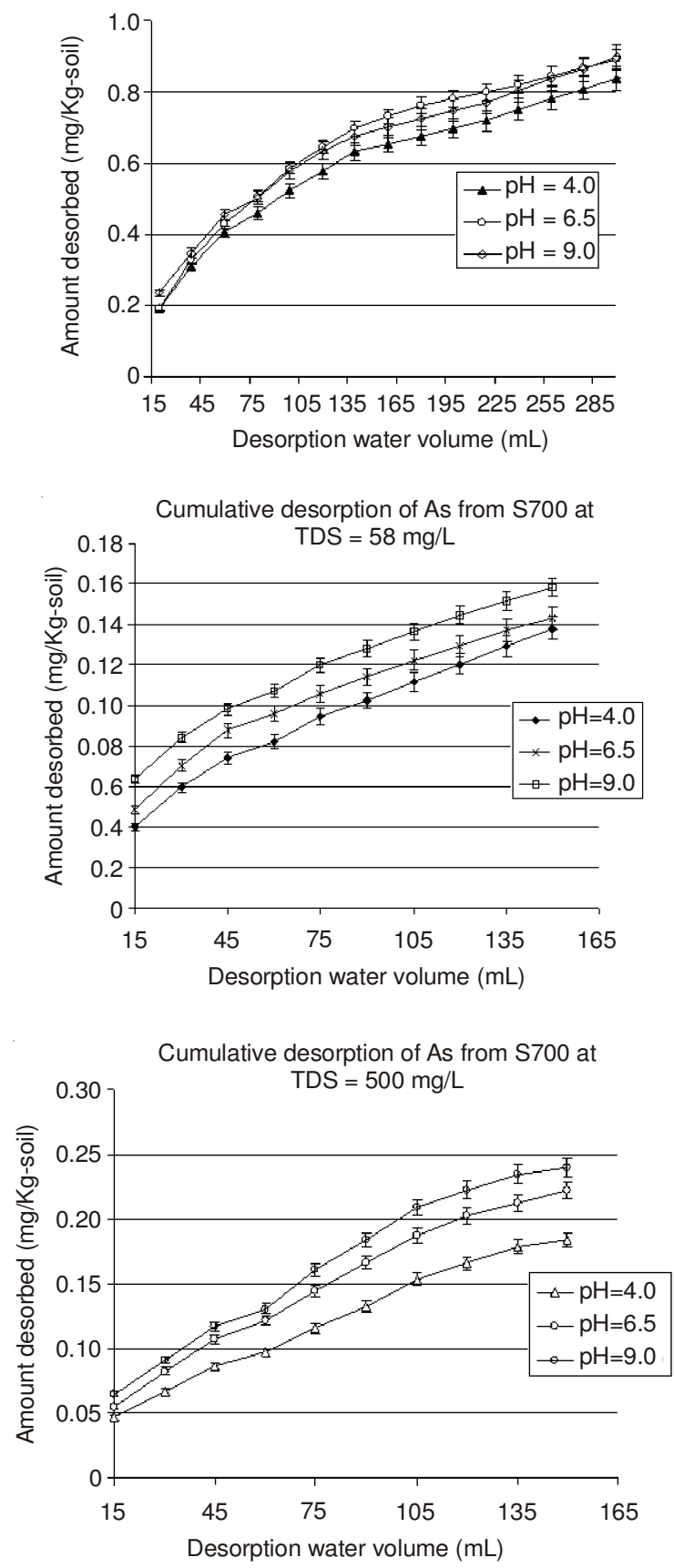

Fig. 4. Effect of pH on cumulative desorption of As from S400 and S700
TABLE-5

ACIDITY CONSTANTS OF ARSENIC COMPOUNDS

\begin{tabular}{lccc}
\hline As compounds & $\mathrm{pK}_{\mathrm{a}, 1}$ & $\mathrm{pK}_{\mathrm{a}, 2}$ & $\mathrm{pK}_{\mathrm{a}, 3}$ \\
\hline $\mathrm{H}_{3} \mathrm{AsO}_{4}$ & 2.25 & 6.76 & 11.60 \\
$\mathrm{As}(\mathrm{OH})_{3}{ }^{* \mathrm{a}}$ & 9.23 & 12.13 & 13.40 \\
\hline
\end{tabular}

of the abundance of carbonate. Regardless of the initial $\mathrm{pH}$ of the desorption solution, the $\mathrm{pH}$ of the soil/water mixture after each $20 \mathrm{~h}$ contact period stayed within the ranges of 8.3-9.4 and 7.5-9.4 for S400 and S700, respectively.

\section{Conclusion}

For S400 and S700 samples, cumulative desorption amount of Ca is, respectively 2050 and $1900 \mathrm{mg} / \mathrm{kg}$-soil with 12 times extraction at $58 \mathrm{mg} / \mathrm{L}$ of TDS water at $\mathrm{pH}=4$. It was found that desorption of $\mathrm{Ca}, \mathrm{Mg}$ and $\mathrm{Ba}$ decreases with increasing $\mathrm{pH}$. For S400 and S700, cumulative desorption amount of As is about $0.9 \mathrm{mg} / \mathrm{kg}$-soil with 15 times extraction at $58 \mathrm{mg} / \mathrm{L}$ of TDS water at $\mathrm{pH}=9$. On the contrary, desorption of As was found to increase slightly with increasing solution $\mathrm{pH}$. Significant desorption of arsenic was observed when a vadose zone soil and an aquifer material collected from the Water Campus Project were contacted with reverse osmosis treated wastewater. The amount of arsenic desorption was a complex function of solution $\mathrm{pH}$, total ionic strength, ionic composition and soil mineral composition. In general, desorption of As increased with increasing solution $\mathrm{pH}$ because it desorbs in the form of oxyanion, although this effect was offset by the less dissolution of $\mathrm{CaCO}_{3}$ at higher $\mathrm{pH}$, which reduced release of carbonate associated arsenic.

\section{ACKNOWLEDGEMENTS}

This work was supported by the National Natural Science Foundation of China (NSFC, No. 51078001), Water Reuse Foundation Project (WRF-06-005-01), Key Special Program on the S\&T for the Pollution Control and Treatment of Waters (No. 2012ZX07103-001-04) and International Corporation Project of Science and Technology of Anhui Province (No. 09080703035).

\section{REFERENCES}

1. L.A. Baker, T. Qureshi and M. Wyman, Water Resour. Res., 34, 1543 (1998).

2. D.W. Nelson and A. Sommers, Proc. Indiana Acad. Sci., 456 (1975).

3. E. Ben-Dor and A. Banin, Method. Commun. Soil Sci. Plant Anal., 201, 75 (1989).

4. M. Polemio and J.D. Rhoades, Soil Sci. Soc. Am. J., 41, 524 (1977).

5. A.L. Page, R.H. Miller and D.R. Keeney, Methods of Soil Analysis. American Society of Agronomy, Inc.: Madison, WI, edn 2 Agronomy. p. 1159 (1982)

6. J.A. Davis and D.B. Kent, in eds.: M.F. Hochella and A.F. White, MineralWater Interface Geochemistry in Reviews in Mineralogy, p. 177 (1990).

7. J.W. Murray, Geochim. Cosmochim. Acta, 39, 505 (1975).

8. L. Jean-Soro, F. Bordas and J.-C. Bollinger, Environ. Pollut., 164, 175 (2012). 